\title{
Evaluation of the effect of surgical and immunological castration of male pigs on boar taint compounds in oral fluid and fat tissue by LC-MS/MS method
}

\author{
Barbara Woźniak $^{1 凶}$, Piotr Cybulski², Artur Jabłoński ${ }^{3}$, \\ Sebastian Witek ${ }^{1}$, Iwona Matraszek-Żuchowska ${ }^{1}$ \\ ${ }^{1}$ Department of Pharmacology and Toxicology, National Veterinary Research Institute, 24-100 Puławy, Poland \\ ${ }^{2}$ Goodvalley Poland, 77-320 Przechlewo, Poland \\ ${ }^{3}$ Faculty of Veterinary Medicine, Warsaw University of Life Sciences, 02-787 Warsaw, Poland \\ bmwozniak@wp.pl
}

Received: May 29, $2020 \quad$ Accepted: November 23, 2020

\begin{abstract}
Introduction: An effective way of preventing undesirable boar taint in pork meat caused by the presence of androstenone, skatole and indole is surgical castration of piglets. This, however, arouses growing social opposition. An alternative method of inhibiting the development of unpleasant odour is immune castration. The aim of the study was to compare the effectiveness of both methods of castration for the elimination of the compounds responsible and to assess the suitability of oral fluid for pre-slaughter predictive testing for boar taint. Material and Methods: The research material was pooled oral fluid and fat samples taken from gilts and surgically and immunologically castrated piglets. The samples were tested with a liquid chromatographytandem mass spectrometry method developed in this research. Results: The compounds giving rise to boar taint were found only sporadically above the accepted limits; only one sample of oral fluid contained skatole at a concentration above $200 \mu \mathrm{g} \mathrm{L} \mathrm{L}^{-1}$ and one contained indole more concentrated than $100 \mu \mathrm{g} \mathrm{L}^{-1}$. Indole above the limit value was also detected in one fat sample. In none of the tested samples was androstenone found. Conclusion: The results indicate the similar effectiveness of both methods of piglet castration on the reduction of compounds generating boar taint. The usefulness of testing oral fluid for the ante-mortem prediction of boar taint has not been fully confirmed and further investigation is needed.
\end{abstract}

Keywords: boars, oral fluid, fat, boar taint, liquid chromatography-tandem mass spectrometry.

\section{Introduction}

For many years in Poland, as in many other European countries, intensive work has been carried out to improve the quality of pork. Consumers pay attention to such meat quality features as colour, taste, smell, tenderness, juiciness and aroma. The taste and smell of meat are significantly influenced by feed additives used in the last fattening period, fish meal, fish oils, and rapeseed products being common examples. An important factor disqualifying meat from further processing is the sexual smell present in carcasses of entire boars (15). Therefore, the castration of piglets is widely practised to prevent the unpleasant sexual odour from meat and additionally reduce aggressive sexual behaviour. From 2018, European Union Member States agreed that surgical castration should be banned as a practice (7) because it is painful for animals and considered unnatural. An alternative to surgical castration is the less stressful immunological castration carried out by means of a preparation having a vaccine-like effect. In 2009, a Pfizer product called Improvac was approved in the EU countries and appeared on the Polish market. The development and function of the testicles are controlled by the gonadotropin-releasing factor, which is secreted from the hypothalamus. Improvac has been proven to be safe for boars from 8 weeks of age. The preparation should be used twice at intervals of at least 4 weeks providing for the second dose to be given 4-6 weeks before slaughter. The boar smell disappears two weeks after the second immunisation and its effect lasts for about 8 weeks, after which the size and function of the testicles return to their original state. The advantages of this method are its zero grace period and causing the animal no pain or stress. After the second immunisation, weakening of typical male behaviours can also occur (18). 
The available studies indicate that immunological castration does not affect either the meat quality or sensory properties negatively (16). In most European countries, approximately $80-100 \%$ of boars reared on large-scale operations are castrated. The exceptions are Ireland and the United Kingdom, where boars are not castrated at all, and Spain, Portugal, and Cyprus, where the percentage of castrated animals is small (16). Only $5-10 \%$ of entire boars have a sexual smell at an organoleptically detectable level. This smell comes mainly from two compounds, androstenone ( $5 \alpha$-androst16-en-3-one) and skatole (3-methylindole) and to a lesser extent from indole (2,3-benzopyrrole). Androstenone is produced in the testes during the maturation of animals and its smell is as urine like or musky $(9,22)$, while skatole and indole are products of the breakdown of tryptophan in the large intestine and have a strong faecal odour $(5,16)$. These compounds are lipophilic and present in high concentrations in adipose tissue of animals, and androstenone is also accumulated in the boar's salivary glands (1). The generally accepted limit values for quantitative differentiation between contaminated and uncontaminated pork samples are $100 \mu \mathrm{g} \mathrm{kg}^{-1}$ for indole, $200 \mu \mathrm{g} \mathrm{kg}^{-1}$ for skatole and $1.00 \mathrm{mg} \mathrm{kg}^{-1}$ for androstenone (13). As the immunological castration of piglets is increasingly used, it became apt to compare both methods of castration for their improvement of meat quality in terms of the presence of compounds responsible for boar taint. It would be highly beneficial for routine boar smell testing to be able to evaluate the animal at the pre-slaughter stage in order to know its future quality as a carcass. Recently there have been reports in the scientific literature on the use of animal saliva for testing at the farm level $(4,8,19)$. Therefore, an attempt was made to develop a method for determining the presence and level of the compounds giving rise to the sexual odour of pigs in oral fluid and to gauge its suitability for assessing meat quality in terms of boar taint at the pre-slaughter stage.

\section{Material and Methods}

Samples. The research material was composed of samples of oral fluid taken on six pig farms in Poland. The animals (DanBred $\times$ Duroc) were divided into groups of 14 animals aged 11-13 weeks. The first group was populated by gilts, the second by gilts and surgically castrated piglets (SC) (50:50), and the third was surgically castrated piglets and the fourth group were immune castrated piglets (IMC) with Improvac. Pooled oral fluid samples were collected from animals in each pen one week before the first immunisation, and then 2 weeks after the first and second immunisation and before planned slaughter (22 weeks-old). Neck fat samples were taken in a slaughterhouse from three groups of animals: gilts (control group), surgically and immunologically castrated boars. Samples after collection were cooled during transport to the laboratory and stored at $-80^{\circ} \mathrm{C}$ until analysis.
Reagents and chemicals. Standards of indole, skatole, androstenone, and 2-methylindole were obtained from Sigma Aldrich (Steinheim, Germany), and testosterone-d2 was sourced from the RIKILT Institute of Food Safety (Wageningen, the Netherlands). All standards were stored in accordance with the recommendations in the certificates. Primary standard stock solutions were prepared in methanol at a concentration of $1 \mathrm{mg} \mathrm{mL} \mathrm{m}^{-1}$ and stored at a temperature below $-18^{\circ} \mathrm{C}$ for no longer than six months. Working standard solutions at concentrations of $1.0 \mu \mathrm{g} \mathrm{mL}^{-1}$ and $0.1 \mu \mathrm{g} \mathrm{mL} \mathrm{mL}^{-1}$ were prepared by appropriate dilution of the stock solutions immediately before the analysis. All chemicals and reagents were of high purity. The solvents: diethyl ether (resi grade) and methanol (resi grade, for highperformance liquid chromatography (HPLC) and liquid chromatography-mass spectrometry (LC-MS)) were purchased from Mallinckrodt Baker (Deventer, the Netherlands). Formic acid (analytical grade) was obtained from Sigma Aldrich, purified water was delivered by a Milli-Q apparatus (Millipore, now Merck, Burlington, MA, USA). Micro-Spin 0.20 $\mu \mathrm{m}$ PTFE filter came from Thermo Fisher Scientific (Waltham, MA, USA).

Sample preparation. Oral fluid samples $(0.5 \mathrm{~mL})$ were fortified with internal standards (2-methylindole at

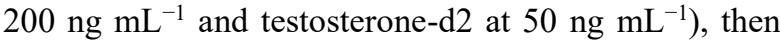
the analytes were extracted with $2 \mathrm{~mL}$ of diethyl ether by vigorously shaking on a vortexer. The contents of the tubes were centrifuged at $4^{\circ} \mathrm{C}$ at $8,000 \mathrm{rpm}$ for $5 \mathrm{~min}$, and the organic phase was separated and evaporated to dryness in a gentle stream of nitrogen at $30^{\circ} \mathrm{C}$. The residue was dissolved in $250 \mu \mathrm{L}$ of methanol, and the extract was transferred to a centrifuge tube with a Micro-Spin filter and subsequently processed with a microcentrifuge at $6,000 \mathrm{rpm}$ for $10 \mathrm{~min}$. Then $75 \mu \mathrm{L}$ of the extract was transferred to glass insert bottles, combined with $75 \mu \mathrm{L}$ of $0.05 \%$ formic acid, and placed in autosampler immediately before liquid chromatography-tandem mass spectrometry (LC-MS/MS) analysis. The fat samples were prepared as described by Bekaert et al. (2). Solid fat of 1-2 $\mathrm{g}$ mass was weighed into the tube and placed in a microwave for $3 \mathrm{~min}$ at $180 \mathrm{~W}$ to be melted. The tube was removed from the microwave and left for $3 \mathrm{~min}$, and then the heating process was repeated until the requisite amount of fat was melted. These samples were transferred into $2 \mathrm{~mL}$ centrifuge tubes in $150 \mu \mathrm{L}$ volumes, and then $750 \mu \mathrm{L}$ of methanol was added and the tube contents were mixed quickly on the vortexer. The tubes were placed in an ultrasonic bath at $40^{\circ} \mathrm{C}$ for approximately $15 \mathrm{~min}$. After the liquid state was obtained, the content was vigorously mixed on the vortexer and then the tubes were placed in a freezer at $<-18^{\circ} \mathrm{C}$ for about $30 \mathrm{~min}$. Next, the contents were centrifuged at $15,000 \mathrm{rpm}$ for $5 \mathrm{~min}$ and $500 \mu \mathrm{L}$ of methanolic extract was transferred to a centrifuge tube with a Micro-Spin filter. Separation of the extract followed on a micro centrifuge at $6,000 \mathrm{rpm}$ for $10 \mathrm{~min}$, after which $200 \mu \mathrm{L}$ of extract and $200 \mu \mathrm{L}$ of $0.05 \%$ formic acid were pipetted to glass insert bottles and the solution was placed in an autosampler. 
The LC-MS/MS analysis was then possible to perform. For each analytical batch, a calibration curve was prepared over the analyte concentration range. Every series of analyses was augmented with spiked samples to verify the quality of the results. The compounds present in the sample were identified on the basis of the characteristic ions for each analyte and the relative retention time of the analytes in the sample in relation to the retention time of the analytes in the spiked sample. For the LC-MS method, the relative retention time tolerance is $2.5 \%$.

LC-MS/MS measurement. The collected research material was tested by LC-MS/MS method on a Nexera X2 UHPLC liquid chromatography system coupled with an MS 8050 triple quadrupole mass spectrometer (both Shimadzu Corporation, Kyoto, Japan) fitted with a dual ion source for simultaneous electrospray and atmospheric pressure chemical ionisation (DUIS ESI/APCI) operating in positive mode. Optimisation of the tandem mass spectrometer operating conditions was carried out by automatically dosing the standard solutions of individual analytes and their internal standards (IS) in order to obtain the correct fragmentation of compounds and satisfactory sensitivity. The optimal conditions of the instrument were as follows: interface temperature of $300^{\circ} \mathrm{C}$, heat block temperature of $300^{\circ} \mathrm{C}$, desolvation line temperature of $245^{\circ} \mathrm{C}$, nebulising gas (nitrogen) flow of $3 \mathrm{~L} \mathrm{~min}^{-1}$, heating gas flow of $10 \mathrm{~L} \mathrm{~min}^{-1}$, and drying gas flow of $10 \mathrm{~L} \mathrm{~min}^{-1}$. Data were acquired in the multiple reaction monitoring (MRM) mode. In Table 1 the conditions for MS detection of indole, skatole and androstenone are presented.

The chromatographic separation was performed on a Poroshell 120-EC C18 column $(150 \mathrm{~mm} \times 2.1 \mathrm{~mm}$; $2.7 \mu \mathrm{m})$ (Agilent Technologies, Santa Clara, CA, USA) with an octadecyl guard cartridge $(4 \mathrm{~mm} \times 2 \mathrm{~mm})$ (Phenomenex, Torrance, CA, USA). The column was maintained at a constant temperature of $45^{\circ} \mathrm{C}$. The eluent $\mathrm{A}$ of the mobile phase consisted of methanol and the eluent $\mathrm{B}$ of $0.05 \%$ formic acid in water. The gradient flow applied is shown in Table 2.

Table 1. LC-MS/MS parameters (MRM) used for identification of indole, skatole and androstenone

\begin{tabular}{|c|c|c|c|}
\hline Analyte & Structure & MRM (mass-to-charge (m/z)) & Collision energy $(\mathrm{eV})$ \\
\hline $\begin{array}{l}\text { Indole } \\
\text { (2,3-benzopyrrole) }\end{array}$ & & $\begin{array}{l}118.0>91.1 \\
118.0>65.0 \\
118.0>39.1\end{array}$ & $\begin{array}{l}23 \\
33 \\
47\end{array}$ \\
\hline $\begin{array}{l}\text { Skatole } \\
\text { (3-methylindole) }\end{array}$ & & $\begin{array}{c}132.5>117.1 \\
132.5>89.0 \\
132.5>90.2\end{array}$ & $\begin{array}{l}22 \\
41 \\
33\end{array}$ \\
\hline 2-methylindole (IS) & & $\begin{array}{c}132.5>117.2 \\
132.5>89.1 \\
132.5>90.0\end{array}$ & $\begin{array}{l}23 \\
41 \\
34\end{array}$ \\
\hline Androstenone & & $\begin{array}{c}273.5>255.3 \\
273.5>93.2 \\
273.5>77.2\end{array}$ & $\begin{array}{l}13 \\
26 \\
25\end{array}$ \\
\hline Testosterone-d2 (IS) & & $\begin{array}{c}291.2>111.1 \\
291.2>99.2\end{array}$ & $\begin{array}{l}26 \\
24\end{array}$ \\
\hline
\end{tabular}

IS - internal standard

Table 2. HPLC gradient

\begin{tabular}{cccc}
\hline Time $(\mathrm{min})$ & Flow $\left(\mathrm{mL} \mathrm{min}^{-1}\right)$ & Eluent A $(\%)$ & Eluent B (\%) \\
\hline 0.01 & 0.35 & 40 & 60 \\
2.00 & 0.35 & 60 & 40 \\
3.00 & 0.35 & 90 & 10 \\
3.99 & 0.35 & 90 & 10 \\
4.00 & 0.45 & 90 & 10 \\
6.00 & 0.45 & 100 & 0 \\
7.00 & 0.45 & 100 & 0 \\
7.01 & 0.35 & 100 & 0 \\
7.10 & 0.35 & 40 & 60 \\
10.00 & 0.35 & 40 & 60 \\
\hline
\end{tabular}


Method validation. In the validation studies, oral fluid and fat samples taken from gilts were used (it having been confirmed that the samples did not contain the analytes tested for), which were enriched with standard solutions to defined concentrations depending on the analyte and matrix. For each matrix, one series of analyses consisting of 7 blank matrix samples and 7 samples enriched at three concentration levels was performed. The validation level depended on the generally accepted limit values for quantitative differentiation between contaminated and uncontaminated pork samples, and these are $100 \mu \mathrm{g} \mathrm{L}^{-1}$ for indole, $200 \mu \mathrm{g} \mathrm{L}^{-1}$ for skatole, and $1.00 \mathrm{mg} \mathrm{L}^{-1}$ for androstenone. These ubiquitously recognised limits were adopted for this stage of the study. For indole the validation levels were 5, 100 and $200 \mu \mathrm{g} \mathrm{L}^{-1}$, for skatole they were 50, 200 and $500 \mu \mathrm{g} \mathrm{L}^{-1}$, and for androstenone 100,500 and $1000 \mu \mathrm{g} \mathrm{L}^{-1}$ were set. Internal standards of 2-methylindole at a concentration of $200 \mu \mathrm{g} \mathrm{L}^{-1}$ and testosterone-d2 at a concentration of $50 \mu \mathrm{g} \mathrm{L}^{-1}$ were also added to each sample. During the method validation, parameters such as selectivity, linearity, recovery, repeatability and limit of quantification (LOQ) were determined.

\section{Results}

The results of the optimisation of the chromatographic separation of the tested compounds are shown in Figure 1. Two C18 columns were tested, differing in grain size and properties: ZORBAX SB-C18 $(50 \times 2.1 \mathrm{~mm}$; $1.8 \mu \mathrm{m}$; Agilent Technologies) and Poroshell 120-EC C18 $(150 \times 2.1 \mathrm{~mm} ; 2.7 \mu \mathrm{m})$.

Proper separation of the tested compounds was obtained on both columns using a mobile phase consisting of a mixture of methanol with $0.05 \%$ formic acid under gradient elution conditions at $45^{\circ} \mathrm{C}$. For further research, however, the Poroshell column was selected, because it achieved better separation of skatole and 2-methylindole (IS) and greater symmetry and intensity of chromatographic peaks.

The validation results of the method developed for determination of compounds giving rise to boar taint in oral fluid and fat tissue are presented in Table 3.

The average apparent recovery (internal standardcorrected) was correct and it ranged from 70 to $121 \%$, depending on the compound and matrix tested.
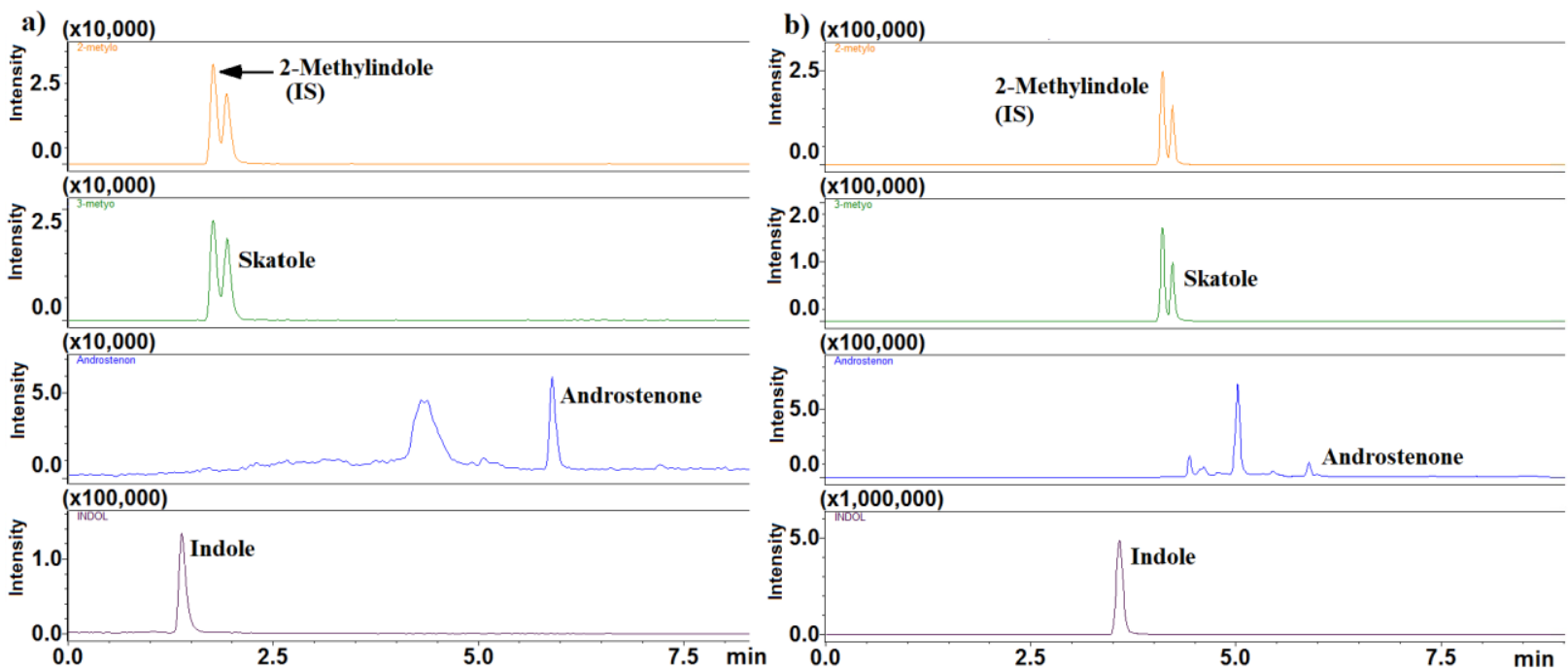

Fig. 1. Chromatographic separation of tested compounds on a column: a) ZORBAX SB-C18 (50 mm $\times 2.1 \mathrm{~mm}, 1.8 \mu \mathrm{m})$ and b) Poroshell 120 -EC C18 $(150 \times 2.1 \mathrm{~mm}, 2.7 \mu \mathrm{m})$

Table 3. LC-MS/MS method validation parameters for indole, skatole and androstenone in swine oral fluid and fat

\begin{tabular}{|c|c|c|c|c|}
\hline \multirow[t]{2}{*}{ Parameter } & & Indole & Skatole & Androstenone \\
\hline & \multicolumn{4}{|c|}{ Oral fluid } \\
\hline Calibration curves & correlation coefficient & 0.9990 & 0.9988 & 0.9967 \\
\hline Matrix calibration curves & correlation coefficient & 0.9980 & 0.9964 & 0.9859 \\
\hline Limit of quantification & $\operatorname{LOQ}\left(\mu \mathrm{g} \mathrm{L}^{-1}\right)$ & 5 & 50 & 50 \\
\hline Repeatability & C.V. $(\%)$ & 28.20 & 30.0 & 24.4 \\
\hline Recovery & $(\%)$ & 75.4 & 70.0 & 95.3 \\
\hline \multirow[t]{2}{*}{ Matrix effect } & $\%$ & 10 & 11 & 30 \\
\hline & \multicolumn{4}{|c|}{ Fat } \\
\hline Calibration curves & correlation coefficient & 0.9988 & 0.9989 & 0.9953 \\
\hline Matrix calibration curves & correlation coefficient & 0.9968 & 0.9875 & 0.9840 \\
\hline Limit of quantification & $\operatorname{LOQ}\left(\mu \mathrm{g} \mathrm{L}^{-1}\right)$ & 5 & 50 & 100 \\
\hline Repeatability & C.V. $(\%)$ & 5.0 & 32.9 & 26.3 \\
\hline Recovery & $(\%)$ & 121.0 & 70.0 & 102.8 \\
\hline Matrix effect & $\%$ & 75.6 & 82 & 27 \\
\hline
\end{tabular}


Table 4. Results of tests of pooled oral fluid samples taken from animals from four experimental groups each consisting of 14 animals

\begin{tabular}{|c|c|c|c|}
\hline Sampling time & Skatole & Indole & Androstenone \\
\hline Gilts (control groups for IMC boars) & $\left(\mu \mathrm{g} \mathrm{L}^{-1}\right)$ & $\left(\mu \mathrm{g} \mathrm{L} \mathrm{L}^{-1}\right)$ & $\left(\mu \mathrm{g} \mathrm{L}^{-1}\right)$ \\
\hline Before giving Improvac to the boars & - & - & - \\
\hline Two weeks after the first boar immunisation with Improvac (pen 1) & - & - & - \\
\hline Two weeks after the first boar immunisation with Improvac (pen 2) & - & - & - \\
\hline \multicolumn{4}{|l|}{ Two weeks after the second immunisation with Improvac before slaughter } \\
\hline Pen 1 & 309.4 & - & - \\
\hline Pen 2 & - & - & - \\
\hline Pen 3 & 106.3 & - & - \\
\hline Pen 4 & 136.4 & 38.6 & - \\
\hline \multicolumn{4}{|l|}{ Immunologically castrated boars (IMC) } \\
\hline Before giving Improvac & 82.5 & - & - \\
\hline Two weeks after the first immunisation with Improvac (pen 1) & - & - & - \\
\hline Two weeks after the first immunisation with Improvac (pen 2) & - & - & - \\
\hline Two weeks after the second immunisation with Improvac, before slaughter & - & - & - \\
\hline \multicolumn{4}{|l|}{ Surgically castrated boars (SC) - samples taken before slaughter } \\
\hline Pen 1 & - & 23.8 & - \\
\hline Pen 2 & 69.7 & 12.2 & - \\
\hline Pen 3 & - & - & - \\
\hline Pen 4 & - & 86.1 & - \\
\hline \multicolumn{4}{|l|}{ Gilts and boars (SC), 50/50 - samples taken before slaughter } \\
\hline Pen 1 & 153.1 & 48.9 & - \\
\hline Pen 2 & - & - & - \\
\hline Pen 3 & - & 125.4 & - \\
\hline Pen 4 & - & - & - \\
\hline
\end{tabular}

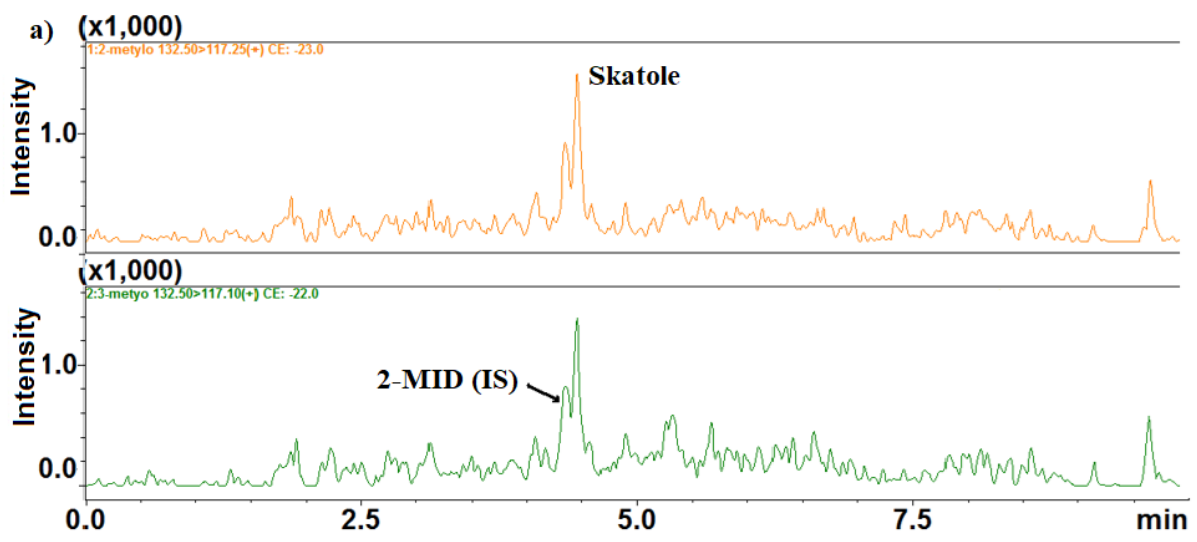

b) $(x 100,000)$

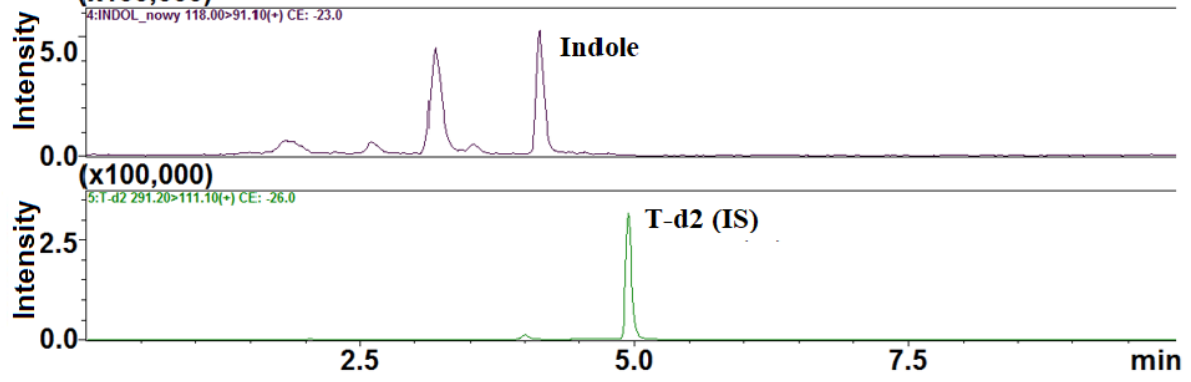

Fig. 2. LC-MS/MS chromatograms of oral fluid samples in which were detected: a) skatole at a concentration of $136 \mu \mathrm{g} \mathrm{L}^{-1}$ (gilts); b) indole with a concentration of $86.1 \mu \mathrm{g} \mathrm{L}^{-1}$ (SC boars) 
Table 5. Results of studies on compounds responsible for boar taint in fat samples taken from gilts, surgically and immunologically castrated boars

\begin{tabular}{|c|c|c|c|}
\hline Gilts & Skatole & Indole & Androstenone \\
\hline Number of samples tested (n) & 15 & 15 & 15 \\
\hline Number of analyte-containing samples & 7 & 11 & 0 \\
\hline $\mathrm{C}_{\text {average }}\left(\mu \mathrm{g} \mathrm{L}^{-1}\right)$ & 65.2 & 25.3 & \\
\hline $\mathrm{SD}\left(\mu \mathrm{g} \mathrm{L}^{-1}\right)$ & 8.0 & 40.9 & \\
\hline $\mathrm{C}_{\min -\max }\left(\mu \mathrm{g} \mathrm{L}^{-1}\right)$ & $57.7-78.3$ & $5.4-146.5$ & \\
\hline \multicolumn{4}{|l|}{ IMC boars } \\
\hline Number of samples tested (n) & 15 & 15 & 15 \\
\hline Number of analyte-containing samples & 10 & 11 & 0 \\
\hline $\mathrm{C}_{\text {average }}\left(\mu \mathrm{g} \mathrm{L}^{-1}\right)$ & 60.3 & 15.6 & \\
\hline $\mathrm{SD}\left(\mu \mathrm{g} \mathrm{L}^{-1}\right)$ & 5.8 & 8.8 & \\
\hline $\mathrm{C}_{\min -\max }\left(\mu \mathrm{g} \mathrm{L}^{-1}\right)$ & $51.3-69.2$ & $5.5-30.0$ & \\
\hline \multicolumn{4}{|l|}{ SC boars } \\
\hline Number of samples tested (n) & 15 & 15 & 15 \\
\hline Number of analyte-containing samples & 7 & 9 & 0 \\
\hline $\mathrm{C}_{\text {average }}\left(\mu \mathrm{g} \mathrm{L}^{-1}\right)$ & 60.3 & 18.4 & \\
\hline $\mathrm{SD}\left(\mu \mathrm{g} \mathrm{L}^{-1}\right)$ & 5.1 & 9.0 & \\
\hline $\mathrm{C}_{\min -\max }\left(\mu \mathrm{g} \mathrm{L}^{-1}\right)$ & $54.0-67.5$ & $5.2-35.2$ & \\
\hline
\end{tabular}

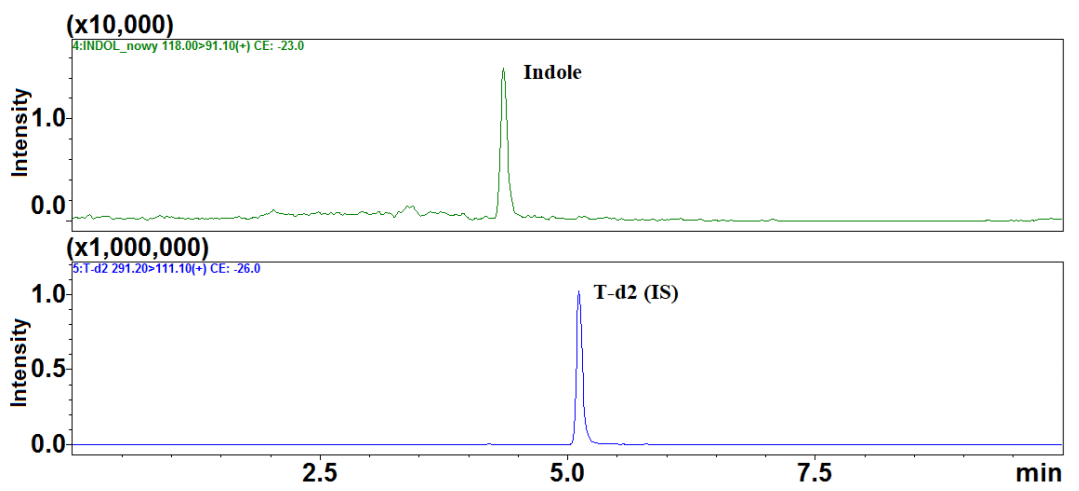

Fig. 3. LC-MS/MS chromatogram of a fat sample taken from an immunologically castrated boar in which an indole concentration of $21 \mu \mathrm{g} \mathrm{L}^{-1}$ was determined

The developed method was characterised by good linearity $(r>0.98)$ and repeatability. The determined limits of quantification for the three compounds were from $5 \mu \mathrm{g} \mathrm{L}^{-1}$ to $100 \mu \mathrm{g} \mathrm{L}^{-1}$. The results of examination of pooled oral fluid samples taken from animals on farms from the three experimental groups and the control group are presented in Table 4 . Of the 20 samples, 6 had skatole above the method's limit of quantification. Only in one sample did the concentration exceed the limit of $200 \mu \mathrm{g} \mathrm{L} \mathrm{L}^{-1}$ established for fat samples. There are no established criteria for oral fluid. These samples were taken from gilts before slaughter. In the boar group, skatole was found in oral fluid prior to administration of Improvac, but neither indole nor androsterone above LOQ was detected. Samples taken after immunological castration did not contain the test compounds. In one sample of oral fluid collected from a surgically castrated boar, a low concentration of skatole was found, and in three samples trace amounts of indole were identified. In the group of mixed gilts and boars, skatole and indole were detected in one sample and indole with a concentration exceeding $100 \mu \mathrm{g} \mathrm{L}^{-1}$ in another.

The LC-MS/MS chromatogram of the samples in which the presence of indole and skatole in the oral fluid was detected is presented in Fig. 2.

The results of testing fat samples for compounds causing boar taint are presented in Table 5 .
Over $50 \%$ of the 45 fat samples tested contained both skatole and indole, but the determined concentration of indole exceeded the limit value in only one sample taken from a gilt, that limit value for this compound being $100 \mu \mathrm{g} \mathrm{L}^{-1}$. The highest average concentrations of indole and skatole were recorded in samples of fat taken from gilts, while in samples taken from castrates the average values determined were slightly lower and very similar. An example of an LC-MS/MS chromatogram of a fat sample in which an indole was found is shown in Fig. 3.

\section{Discussion}

The first step in developing an analytical procedure is to determine the detection conditions for the compounds tested. The research began with the optimisation of the QTRAP 5500 tandem mass spectrometer operating conditions by dosing standard solutions of individual analytes and IS. The compounds of interest could not be detected with this apparatus, which resulted from the use of electrospray ionisation mode (ESI). Therefore, optimisation was undertaken on a Shimadzu apparatus, which is equipped with a dual ion source granting both electrospray and atmospheric pressure chemical ionisation. The Interface Setting 
Support application was used for ion source optimisation. This software allows selection of the most intense transitions and gives optimal sensitivity. Positive ionisation was used in MS/MS analysis, and spectral data collection was carried out in MRM mode. At least two daughter ions were obtained for each compound, thus meeting the criterion required for confirmatory methods (Table 1). To obtain the correct chromatographic separation of the tested compounds, two C18 columns were tested, differing in grain size and properties. In addition, the effect of column temperature on the separation of compounds as well as the composition and flow rate of the mobile phase were investigated. Sufficient peak resolution of the tested compounds was achieved on the Poroshell column using a mobile phase consisting of a mixture of methanol with $0.05 \%$ formic acid under gradient elution conditions at $45^{\circ} \mathrm{C}$ (Fig. 1). In order to select the optimal solvent for extracting analytes from oral fluid samples, based on the literature data $(11,17,20,21)$ and our experience, the suitability of different polarity of solvents or their mixtures was tested: diethyl ether, ethyl acetate, acetonitrile, dichloromethane, n-hexane/2-propanol (98: 2, v/v), petroleum ether/tert-butyl methyl ether $(70: 30, \mathrm{v} / \mathrm{v})$ and n-hexane/methanol $(70: 30, \mathrm{v} / \mathrm{v})$. Optimisation tests were carried out on fortified oral fluid samples, but sufficient chromatographic signal intensity was not obtained even in a single case. It was considered that the cause of these difficulties could be the interactions between proteins present in the matrix and indoles. To reduce sulphide bonds, dithiothreitol was used, which is a strong reducing agent. Significant amplification of the chromatographic signals was obtained, indicating good indole extraction efficiency with the help of several tested solvents. The modifications introduced in the sample purification did not have the desired effect, because the required repeatability was not achieved. However, it was found that all stages associated with the evaporation of organic extracts at a temperature of $60^{\circ} \mathrm{C}$ adversely affected the repeatability of the method, which results from the impermanence of the analytes studied. Therefore, the extraction of analytes from oral fluid samples with diethyl ether, whose boiling point is $34.6^{\circ} \mathrm{C}$, proved to be an effective way to improve the repeatability of the method.

For fat samples, purification was performed as described by Bekaert et al. (2). For the extraction of the tested compounds, methanol was used and solvent evaporation stages were eliminated during the extract purification. This was achieved by reducing the methanol volume to $750 \mu \mathrm{L}$ and using freezing and centrifugation at $15,000 \mathrm{rpm}$ to purify the sample. The results of validation of the LC-MS/MS method for indole, skatole and androstenone assessment in oral fluid and adipose tissue of pigs presented in Table 3 confirm that the method is suitable for testing the compounds responsible for sexual odour in these matrices. Correct apparent recovery was obtained for all compounds tested with the criteria set out in Commission Decision 2002/657/EC (6), falling within the range of 70.0-121.0\%. The developed method is characterised by correct repeatability, because the $\mathrm{CV}$ coefficient does not exceed $30 \%$. The limit of quantification ranges from $5 \mu \mathrm{g} \mathrm{L}^{-1}$ to $100 \mu \mathrm{g} \mathrm{L}^{-1}$ depending on the compound and matrix. The lowest point of the calibration curve on the matrix was taken as the limit of quantification. The determined detection limits are much lower than those established for these compounds' limit values in fat samples of $100 \mu \mathrm{g} \mathrm{L}^{-1}$ for indole, $200 \mu \mathrm{g} \mathrm{L}^{-1}$ for skatole and $1000 \mu \mathrm{g} \mathrm{L}^{-1}$ for androstenone (13). The linearity of the method was checked on indole and skatole standard solutions for the concentration range $10-800 \mu \mathrm{g} \mathrm{L}^{-1}$ and androstenone for the range $100-2000 \mu \mathrm{g} \mathrm{L}^{-1}$. The calculated correlation coefficients for the curves of the standard solutions exceed the value of 0.98 , which indicates good linearity of the signal. Calibrations with matrix were also found to be linear. Matrix effects were evaluated by comparison of the regression lines calculated from standards with and without matrix, based on the slope (3). For all the compounds, regardless of the matrix, a significant suppression of the chromatographic signal was observed (ME from 10\% to $82 \%$ ). It is recognised that acceptable suppression or enhancement of the analytical signal should not exceed $20 \%$, which means that the matrix effect is between 80 and $120 \%$ (14). Therefore, for quantitative analysis a matrix-matched calibration curve was applied.

The method was used to test pooled samples of oral fluid taken on farms from gilts and boars castrated surgically or immunologically. The presence of boar taint compounds was found sporadically in the samples tested, and only one fluid sample contained skatole and one indole with concentrations exceeding the determined limit value of $200 \mu \mathrm{g} \mathrm{L}^{-1}$ and $100 \mu \mathrm{g} \mathrm{L}^{-1}$, respectively. The sample in which the high concentration of skatole was determined was taken from the gilts before being brought to the slaughterhouse. Because skatole and indole are products of bacterial degradation of the amino acid tryptophan in the large intestine, their presence in pig tissues may be affected by diet or the environment (13). It has been reported that the introduction into the diet of inulin present in chicory root, pure potato starch or butyric acid has a positive effect on the level of skatole and indole in the body, contributing to the elimination of unwanted odour $(12,18)$.

Environmental influences are usually related to the management, hygiene standard and adequacy of ventilation of farms. It has been shown that these factors affect skatole levels in all pigs, regardless of sex (23). Therefore, the presence of indole and skatole in gilts is a natural phenomenon. The highest concentration of indole was found in the pooled sample of oral fluid taken from the group of mixed animals consisting of gilts and surgically castrated boars. In a different sample, skatole and indole were detected simultaneously with slightly lower concentrations. Some studies show a negative effect of the presence of gilts on the occurrence of boar taint in pigs (12). That is why such a group of animals 
was included in the experiment. The highest indole and high skatole concentration found in this group of animals compared to groups of boars only, could confirm this theory. It should be added that the presence of the compounds which produce the boar malodour was found primarily in samples of fluid taken from animals just before being brought to the slaughterhouse. In the boar group, skatole was found in oral fluid prior to administration of Improvac, but neither indole nor androsterone above LOQ was detected. Samples taken after immunological castration did not contain the tested compounds. In one sample of oral fluid collected from surgically castrated pigs, a low concentration of skatole was found, and in three samples trace amounts of indole were distinguished. Higher levels of skatole and indole were also found in slaughterhouse samples of fat taken from gilts than in samples from boars, as evidenced by the range of determined concentrations as well as the mean values (Table 5). The determined indole concentration only exceeded the limit value in one fat sample taken from gilts, which for this compound is $100 \mu \mathrm{g} \mathrm{L}^{-1}$. However, regardless of the method used to castrate the piglet, very similar concentrations of skatole and indole were found in fat samples. Student's t-test was used to compare the results between the studied groups and no significant differences between the mean concentrations of the tested compounds were confirmed. In none of the tested samples, either of oral fluid or of fat, was the presence of androstenone above the limit of quantification of the method confirmed. Sex steroids, such as testosterone and androstenone, inhibit the hepatic metabolism of skatole, which allows it to accumulate in the animals' fat (13). Therefore, the absence of androstenone in castrated piglets may be the reason for lower concentrations of skatole and indole in their tissues. The obtained research results indicate that immune castration is as effective as the inhumane surgical castration of piglets in eliminating an undesirable smell from pork. The conducted research has not clearly confirmed that oral fluid may be useful for testing for boar taint at the in vivo stage. Although the concentrations of the compounds tested in oral fluid collected from castrated boars are lower than in fluid samples collected from gilts, for reliable assessment of the usefulness of this matrix, the results obtained should also be related to the concentrations of these analytes in the fluid of entire pigs.

Conflict of Interests Statement: The authors declare that there is no conflict of interests regarding the publication of this article.

Financial Disclosure Statement: This study was supported by the National Veterinary Research Institute in Puławy, Poland (Project no. S-280).

Animal Rights Statement: None required.

\section{References}

1. Babol J., Squires E.J.: Quality of meat from entire male pigs. Food Res Int 1995, 28, 201-212, doi: 10.1016/0963-9969(95)93528-3.

2. Bekaert K.M., Vanden Bussch J., Francoisa S., Tuyttens F.A.M., De Brabander H.F., Vandendriessche F., Vanhaecke L.: A validated ultra-high performance liquid chromatography coupled to high resolution mass spectrometry analysis for the simultaneous quantification of the three known boar taint compounds. J Chrom A, 2012, 1239, 49-55, doi: 10.1016/j.chroma.2012.03.060.

3. Buttinger G., Karasek L., Verlinde P., Wenzl T.: In house validation of a reference method for the determination of boar taint compounds by LC-MSMS. JRC Validated Methods, Reference Methods and Measurements. European Commission, Publication Office of the European Union, Luxembourg, 2014, doi: $10.2787 / 88600$.

4. Caramelo D., Rosado T., Oliveira V., Rodilla J.M., Rocha P.M.M., Barroso M., Gallardo E.: Determination of antipsychotic drugs in oral fluid using dried saliva spots by gas chromatographytandem mass spectrometry. Anal Bioanal Chem 2019, 411, 61416153, doi: 10.1007/s00216-019-02005-8.

5. Claus R., Weiler U., Herzog A.: Physiological aspects of androstenone and skatole formation in the boar - a review with experimental data. Meat Sci 1994, 38, 289-305, doi: 10.1016/0309-1740(94)90118-x.

6. Commission of the European Communities: Commission Decision No. 2002/657/EC of 12 August 2002 implementing Council Directive 96/23/EC concerning the performance of analytical methods and the interpretations of results. OJ L221/8, 17/08/2002, 8-36.

7. Commission of the European Communities: Commission Implementing Decision of 27 April 2011 amending Decision $89 / 471 /$ EEC authorising methods for grading pig carcasses in Germany. OJ L1 10/54, 29/04/2011, 29-33.

8. Drummer O.H.: Drug Testing in Oral Fluid. Clin Biochem Rev 2006, 27, 147-159.

9. European Food Safety Agency (EFSA): Welfare aspects of the castration of piglets. Opinion of the Scientific Panel on Animal Health and Welfare on a request from the Commission related to welfare aspects of the castration of piglets. EFSA J 2004, 91, 118, doi: 10.2903/j.efsa.2004.91.

10. Fredriksen B., Font I Furnols M., Lundström K., Migdał W., Prunier A., Tuyttens F.A.M., Bonneau M.: Report of PIGCAS Work Project 2: Practice. Assessment of the extent of the practice of castration and how it is performed in different European countries. PIGCAS Project, sine loco: 1-35, doi: 10.1017/S1751731109004674.

11. Haugen J.-E., Brunius C., Zamaratskaia G.: Review of analytical methods to measure boar taint compounds in porcine adipose tissue: The need for harmonised methods. Meat Sci 2012, 90, 9-19, doi: 10.1016/j.meatsci.2011.07.005.

12. Heyrman E., Millet S., Tuyttens F.A.M., Ampe B., Janssens S., Buys N., Wauters J., Vanhaecke L., Aluwé M.: On farm intervention studies on reduction of boar taint prevalence: Feeding strategies, presence of gilts and time in lairage. Res Vet Sci 2018 , 118, 508-516, doi: 10.1016/j.rvsc.2018.05.008.

13. Kyle J.M.: Effects of immunological castration (Improvest ${ }^{\circledR}$ ) on further processed belly characteristics and commercial bacon slicing yields of heavy weight finishing pigs. Thesis. The Ohio State University 2013.

14. León N., Roca M., Igualada C., Martins C. P. B., Pastor A., Yusá V.: Wide-range screening of banned veterinary drugs in urine by ultra-high liquid chromatography coupled to high-resolution mass spectrometry. J Chromatogr A 2012, 1258, 55-65, doi: 10.1016/j.chroma.2012.08.031.

15. Migdał W., Migdał Ł.: Wykastrować zapach? (in Polish). Magazyn Przemysłu Mięsnego, Jakość 2009, 11-12, 44- 46.

16. Pejsak Z., Truszczyński M.: Immunocastration of boars (in Polish). Życie Weterynaryjne 2009, 84, 374-376. 
17. Rius M.A., García-Regueiro J.A.: Skatole and indole concentrations in Longissimus dorsi and fat samples of pigs. Meat Sci 2001, 59, 285-291, doi: 10.1016/S0309-1740(01)00081-X.

18. Skrzypczak E., Szulc K., Zaworska A., Panek A., Buczyński J.T.: Methods of eliminating the sexual odour of boars (in Polish). Postępy Nauk Rolniczych 2011, 4, 105-114.

19. Turpeinen U., Hämäläinen E.: Determination of cortisol in serum, saliva and urine. Best Pract Res Clin Endocrinolog Metab 2013, 27, 795-801, doi: 10.1016/j.beem.2013.10.008.

20. Verplanken K., Wauters J., Vercruysse V., Aluwé M., Vanhaecke L.: Development and validation of a UHPLC-HR-Orbitrap-MS method for the determination of androstenone, skatole and indole in porcine meat and meat products. Food Chem 2016, 190, 944-951, doi: 10.1016/j.foodchem.2015.06.052.

21. Wauters J., Vanden Bussche J., Verplanken K., Bekaert K.M., Aluwé M., Van Den Broeke, A., Coussé A., Buys N., Vanhaecke L.:
Development of a quantitative method for the simultaneous analysis of the boar taint compounds androstenone, skatole and indole in porcine serum and plasma by means of ultra-high performance liquid chromatography coupled to high resolution mass spectrometry. Food Chem 2015, 187, 120-129, doi: 10.1016/j.foodchem.2015.04.066.

22. Wysocki C.J., Dorries K.M., Beauchamp G.K.: Ability to perceive androstenone can be acquired by ostensibly anosmic people. Proc Natl Acad Sci U S A 1989, 86, 7976-7978, doi: 10.1073/pnas.86. 20.7976 .

23. Zamaratskaia G., Andersson H. K., Ghen G., Andersson K., Madej A., Lundstrom K.: Effect of a gonadotropin releasing hormone vaccine (Improvac) on steroid hormones, boar taint compounds and performance in entire male pigs. Reprod Domest Anim 2008, 43, 351-359, doi: 10.1111/j.1439-0531.2007.00914.x. 